\title{
Breast cancer metastatic to the colon 20 years after bilateral mastectomy
}

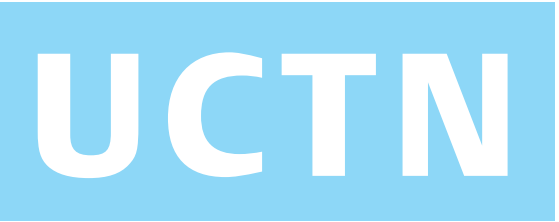

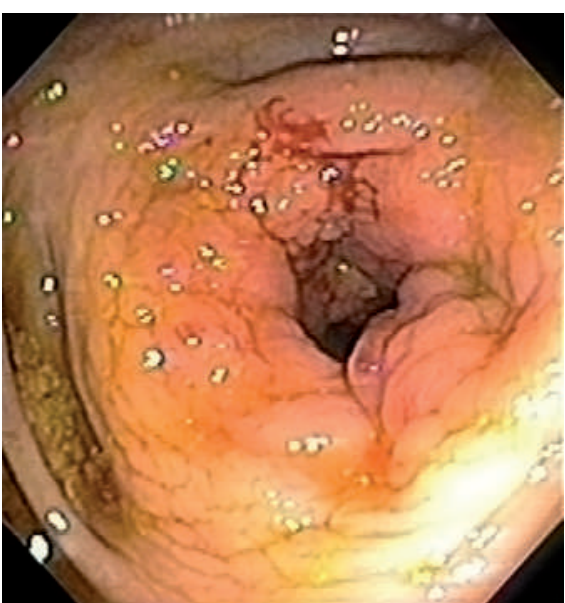

Figure 1 A circumferential friable mass lesion in the ascending colon.

In 1985, a 63-year-old woman underwent left modified radical mastectomy and prophylactic right mastectomy for infiltrating lobular carcinoma, stage T3N1M0, and received adjuvant chemotherapy. At a screening colonoscopy in 2002, she was found to have diverticulosis. In 2005, the patient developed left lower quadrant abdominal pain, which responded to antibiotics; she was presumed to have diverticulitis and was referred to a surgical clinic. Three weeks later, she underwent elective laparoscopic resection of the left colon.

Intraoperatively, a mass was found at the rectosigmoid junction, and a frozen section initially demonstrated malignant cells. A left hemicolectomy was performed. During laparotomy, a firmness $2 \times 3 \mathrm{~cm}$ in size was noted in the right colon. The proximal abnormality was left in place pending final pathology. Once the patient had recovered from surgery, a colonoscopy was carried out in order to visualize the ascending colon. A circumferential friable mass lesion was seen just above the ileocecal fold, and biopsies were obtained (Figure $\mathbf{1}$ ).

Biopsies of both masses revealed carcinoma, with tumor cells diffusely infiltrating the submucosa, muscularis propria, and subserosa, many forming single files. Im-

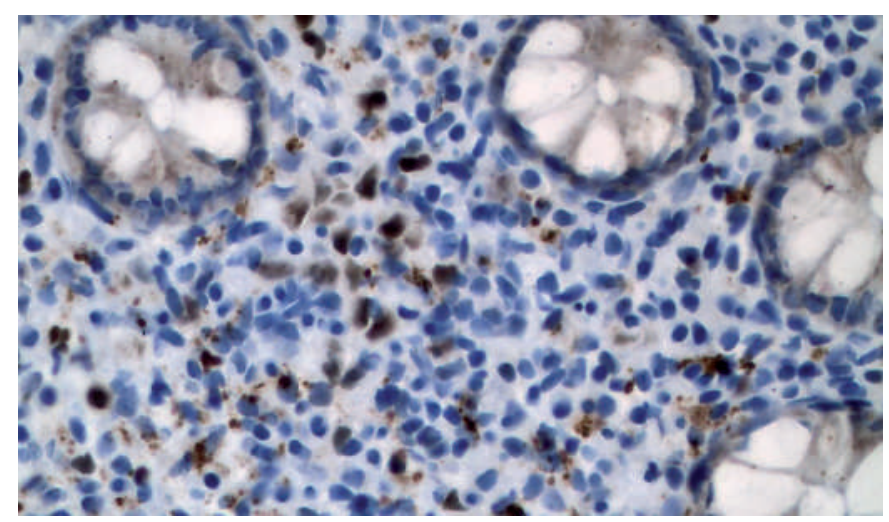

Figure 2 Positive estrogen-receptor staining in the pathology specimen from the endoscopic biopsy of the right colon mass. There are small, round, relatively uniform tumor cells (stained brown) scattered in the lamina propria (estrogen-receptor stain, original magnification $40 \times$ ).

munohistochemically, the tumor was positive for estrogen receptor (>95\%, 2-3+) and pankeratin, features which are both consistent with metastatic lobular breast cancer (Figure 2).

Metastases from breast cancer to the gastrointestinal tract, and particularly the colon, are extremely rare $[1,2]$. The clinical presentation may vary from an asymptomatic abdominal mass to a stenotic lesion causing obstruction, or the symptoms may mimic ulcerative colitis or diverticulitis, as in this case $[1,3,4]$. Although certain features may suggest metastasis rather than primary cancer, radiographic differentiation between the two is particularly difficult during the later stages of disease [5]. If possible, histopathological and immunohistochemical comparison with the original breast cancer specimen should facilitate a correct diagnosis and dictate the appropriate management.

Endoscopy_UCTN_Code_CCL_1AD_2AC

T. Defrawi'1, A. Goyal' ${ }^{2}$ X. Duan², M. Kott², C. P. Fischer ${ }^{3}$, D. G. Adler ${ }^{4}$

${ }^{1}$ Texas Tech. University Medical School, El Paso, Texas, USA

2 Dept. of Pathology, University of Texas Houston Medical School, Houston, Texas, USA

${ }^{3}$ Dept. of Surgery, University of Texas Houston Medical School, Houston, Texas, USA
${ }^{4}$ University of Texas - Houston Medical School, Department of Internal Medicine, Division of Gastroenterology and Hepatology, Houston, Texas, USA.

\section{References}

${ }^{1}$ Law WL, Chu KW. Scirrhous colonic metastasis from ductal carcinoma of the breast: report of a case. Dis Colon Rectum 2003; 46: $1424-1427$

2 Schwarz RE, Klimstra DS, Turnbull ADM. Metastatic breast cancer masquerading as gastrointestinal primary. Am J Gastroenterol 1998; 93: 111 - 114

${ }^{3}$ Melnick GS, Rosenholtz MJ. Metastatic breast carcinoma simulating ulcerative colitis: report of a case. AJR Am J Roentgenol 1961; 86: $702-706$

${ }^{4}$ Rabau MY, Alon RJ, Werbin N, Yossipov Y. Colonic metastases from lobular carcinoma of the breast: report of a case. Dis Colon Rectum 1988; 31: $401-402$

${ }^{5}$ Yokota T, Kunii Y, Kagami M et al. Metastatic breast carcinoma masquerading as primary colon cancer. Am J Gastroenterol 2000; 95: $3014-3016$

\section{Corresponding Author}

\section{G. Adler, M.D.}

Dept. of Gastrointestinal Endoscopy University of Texas - Houston Medical School MSB 4.2346431 Fannin Houston, Texas 77030

USA

Fax: $\quad+1-713-500-6699$

E-mail: douglas.adler@uth.tmc.edu 